\title{
Paciente con síndrome de Down y diabetes mellitus en programa de hemodiálisis
}

\author{
María Bravo Herrero, Lucía López-Pintor Muñoz, Nieves López Castillo, María Parreño Alcolado, \\ Concepción Fernández Ortega
}

Centro de Hemodiálisis Asyter Alcazar de San Juan. Ciudad Real

\section{Introducción:}

Varón de 35 años con síndrome de Down, Diabetes Mellitus tipo 1, Trombosis venosa profunda en miembro inferior izquierdo en 1999 y enfermedad renal crónica estadío 5 secundaria a posible glomerulonefritis crónica. No lee ni escribe, dependiente para las actividades básicas de la vida diaria, come dieta triturada por falta de piezas dentarias. Acude diariamente a un centro ocupacional donde come y participa en actividades para el desarrollo cognitivo y psicomotriz. Vive con dos hermanos. Su padre era diabético y falleció por Infarto Agudo de Miocardio y su madre falleció por neoplasia uterina. En diciembre de 2011 es remitido del Servicio de Prediálisis a nuestra unidad de Hemodiálisis para iniciar tratamiento renal sustitutivo. No era candidato a Diálisis Peritoneal ni a trasplante renal. Al inicio destacaba una importante sobrehidratación, desnutrición calórico-proteica y no presentaba sintomatología urémica. Portaba una FAVI braquiocefálica izquierda normofuncionante. Desde el punto de vista estricto de la técnica hemodialítica consideramos que el paciente ha tenido una buena adaptación (buena tolerancia a las punciones, al tiempo prescrito, a las ultrafiltraciones requeridas y a la hemostasia asistida) Con el paso de los meses ha desarrollado una Polineuropatía distal, sensitivo motora, de tipo axonal, severa en miembros inferiores y moderada en miembros superiores, que lo ha llevado a la paraparesia y a desplazarse en silla de ruedas. Con respecto a los parámetros hematológicos y bioquímicos, éstos han mejorado desde su llegada y en relación a la eficacia dialítica se vienen logrando los objetivos.

\section{Discusión:}

Nuestra unidad se vio alterada por este caso, ya que en algunos momentos era necesaria la presencia de varios profesionales sanitarios para prestar atención exclusiva, debido a las dificultades para adaptarse a los cambios puntuales propios de una unidad de hemodiálisis. La coagulación siempre es realizada por el personal de enfermería. Inicialmente mostraba desconfianza, temor e inseguridad lo que suponía mucho esfuerzo a la hora de entrar en sala y adaptarse al medio. Ha habido episodios aislados de agitación y ansiedad, siendo incluso necesaria la presencia de un familiar sala. A pesar de todo actualmente presenta un buen estado general, y ha establecido relaciones interpersonales dentro de la Unidad. La relación familia - personal es excelente, ya que muestran mucho interés y colaboración. Debido a la calidad asistencial que le presta su familia, en la actualidad se está replanteado la posibilidad de incluirlo en la Lista de Trasplante.

\section{Conclusión:}

Destacamos la labor de todo nuestro equipo para adaptarse a esta nueva situación a la que no estábamos preparados, ya que casos como el que tratamos es una situación aislada, teniendo en cuenta la muy baja prevalencia de estos pacientes en hemodiálisis. Tras nuestra experiencia en este caso, queremos resaltar la importancia de una formación adicional previa para conseguir una mayor calidad asistencial. Agradecemos a los familiares por la colaboración ofrecida y por el buen cuidado del paciente, haciendo que la hemodiálisis pase a formar parte de su vida de la mejor manera posible. 


\section{Referencias Bibliográficas}

1. "Vivir con el Síndrome de Down: una introducción para padres y profesores". Sue Buckley, Gilliam Bird, Ben Sacks, Juan Perera (2006). Editorial CEPE, Madrid.

2. "Síndrome de Down: los hechos". Mark Selikowitz (1992). Instituto Nacional de Servicios Sociales, Madrid.

3. "Síndrome de Down: aspectos específicos". Juan Perera (1994). Editorial MASSON, Barcelona.
4. "Síndrome de down: lectura y escritura". María Victoria Troncoso, María Mercedes Del Cerro (1999). Editorial MASSON.

5. "Tratado de hemodiálisis" ( $2^{\mathrm{a}}$ edición). R. Jofré; J.M. López Gómez, J. Luño, R. Pérez García, P. Rodríguez Benítez (2006). JIMS Editorial Médica.

6. "Manual de diálisis" ( $2^{\mathrm{a}}$ edición). J.T. Daugirdas, P.G. Blake, T.S. Ing (2003). Editorial MASSON. 